\title{
The Impact of Translators' Academic Experience on Their Translation Quality
}

\author{
Mohsen Varzande ${ }^{1,2}$ \& Esmaeil Jadidi \\ ${ }^{1}$ Department of English, Marvdasht Branch, Islamic Azad University, Marvdasht, Iran \\ ${ }^{2}$ Department of English, Fars Science and Research Branch, Islamic Azad University, Marvdasht, Iran \\ Correspondence: Esmaeil Jadidi, Department of English, Marvdasht Branch, Islamic Azad University, Marvdasht, \\ Iran. Tel: 98-917-314-5087. E-mail: esmaeil.jadidi@yahoo.com
}

\author{
Received: May 13, 2015 Accepted: August 6, 2015 Online Published: August 11, 2015 \\ doi:10.5539/elt.v8n9p11 URL: http://dx.doi.org/10.5539/elt.v8n9p11
}

\begin{abstract}
Translators differ from each other in many ways in terms of their knowledge and professional conditions that may directly influence their translation. The present study aimed at investigating the impact of translators' academic experience on their translation quality. Following a causal-comparative study, a sample of 100 male and female professional translators, working in official or non-official translation offices or as freelance translators, were selected using purposive sampling method. The participants were divided into two groups each containing 50 individuals with and without a degree in translation, respectively. The participants were asked to translate a paragraph including 232 words, from Orwell's 1984 novel, to assess their translation quality. To do this, Waddington's model D (2001) was used as the marking system. For data analysis, inferential statistical procedures including independent sample t-test was used in order to investigate the research hypothesis. Results showed that translators' academic experience in translation significantly affects their translation quality. The results also clearly depicted that the translation quality of translators with academic experience was significantly better than that of those without academic experience.
\end{abstract}

Keywords: translation quality, academic degree, translator

\section{Introduction}

Translators differ from each other in many ways mainly due to their knowledge and professional and psychological conditions. A combination of these individual differences and characteristics may directly influence their translation quality (Shojaee \& Sahragard, 2012; Karimnia \& Mahjubi, 2013; Shangarffam \& Abolsaba, 2009; Dongfeng \& Dan, 1999).

Nowadays, due to the great need for competent translators, the basic step of a planned and organized approach is the mastery over theoretical frameworks. Flourishing of translation theories and new ideas toward the process of translation was a turning point in translation studies (Farahzad et al., 2010).

On the other hand, over the past decades, few studies have directly examined the relationship between individuals' level of education and their job performance. According to NG and Feldman (2009), years of work experience did not moderate the education-performance relationship due to the fact that work experience indicates the quantity not the quality; nevertheless, some dimensions of performance are influenced by education. For instance, Saridakis and Kostoupolou (2003) found that professional translators without an academic degree in Translation do not focus on the revision stage; this can challenge the quality of their translation; on the contrary, qualified translators and academics recognize the significance of this stage. Thus, the academic status of the translator should be taken into account as one of the elements of his/her sense of responsibility which undoubtedly influences the process and the quality of translation.

Furthermore, a translator is expected to have good knowledge of other fields to perform a better job (Schutte, 2001). While people tend to specialize in as few as narrow areas as possible, translators are expected to have a very good knowledge of all the domains with which their work interferes. That is why translation students expect to receive solid and complex training meant to enable them to face the challenges of translating in real world situations. Most of the students expect their teachers to give them the opportunity to acquire various specific knowledge and skills associated with their future profession (Cozma \& Dejica-Cartis, 2013). 
A brief review of the literature indicates that translators' degree in translation, academic experience and academic knowledge positively affect the quality of the translation product, the process of translating and producing a good translation, respectively (Saridakis \& Kostoupolou, 2003; Dongfeng \& Dan, 1999; Albustan, 1993). On the other hand, it has been argued that investigating Emotional Intelligence is both necessary and desirable to gain a deeper understanding of the translation process (Saridakis \& Kostoupolou, 2003). Also, Emotional Intelligence has proved to be correlated with successful task performance (Schutte, 2001). As certain career fields place a higher emphasize on Emotional Intelligence abilities than others, further research should focus on a specific Emotional Intelligence construct which successfully predicts translators' job performance (Shipley et al., 2010).

To sum up, academic experience is one of those factors that seem to affect the translator's performance and his/her translation quality. Therefore, the focus of the present study is to investigate whether the translators' academic degree in translation influence their translation quality.

This study was designed to seek answers to the following question:

Is there any significant relationship between translator's academic degree and their translation quality?

Based on the aforementioned research question, the following hypothesis was formulated:

There is a significant relationship between translator's academic experience and their translation quality.

\section{Review of Literature}

A review of literature indicates that different researchers have approached the concept of quality from different perspectives, taking into account, different factors which seemed or claimed to influence translation quality. For instance, Malkiel's (2006) study revealed that higher-quality of translations and better performance of translators is related to their training and experience. In their study, Shojaee and Sahragard (2012) found that there is a positive correlation between being a risk-taker and the quality of translation among BA Translation Studies students. Pourgharib and Dehbandi (2013) showed that translator's personality had no impact on translation quality of narrative texts.

In the field of translation studies, some studies have focused on the influence of translator's academic knowledge on the quality of their translations. For instance, according to Albustan (1993), the role of the translator's academic knowledge have been implicitly recognized which enable him to produce a 'good' translation and to facilitate quality control. According to Holljen (1999) the education of translators is of paramount importance in enhancing the quality of their work. She added that the need for integrating the aspect of terminology science is obvious while for experienced translators without any translator-specific education, the connection between various aspects of terminology science and their everyday work comes more or less as a revelation.

Cultural assessment in clinical Psychiatry, formulated by the committee on cultural psychiatry group for advancement of Psychiatry (2002), also found that the translator's level of education influences the translation quality so that a translator with a low educational level might have difficulty translating some specialized texts including psychiatry. Saridakis and Kostoupolou (2003) also observed that some professional translators, mainly without a degree in Translation, seem to ignore or underestimate the role of revision as pertains to the quality of the translation product while qualified translators acknowledge the importance of the revision stage. According to Iida (2008), one of the crucial elements to enhance the quality of translation is knowledge of pragmatics, more specifically when, how, and in what situation the target language is used in the society. The results of Farahzad's (2010) study shed more light on the positive effects of incorporating teaching functional translation theories on translation quality of translator trainees. Finally, according to Shojaee and Sahragard (2012), the translator's academic experience may play an important role in predicting the quality of his/her translation. Translation trainees being aware of theoretical frameworks and having knowledge of theories of translation may affect the quality of the translation product.

\section{Methodology}

\subsection{Design}

The design of this quantitative study was causal-comparative in nature. In this design, cause was identified as the translators' academic degree and its effect on the translation quality remained to be investigated.

\subsection{Instruments and Materials}

Waddington's translation quality assessment model D was used to determine participants' translation quality. This model is designed and validated by Waddington (2001). Model D actually consists of combining error analysis and holistic methods of Waddington model in a proportion of 70/30, respectively. To do so, a paragraph 
containing 246 words was given to be translated into Persian; the text was part of the Orwell's 1984 novel.

\subsection{Participants}

The population under study was a group of professional translators, working in official and non-official translation centers, and freelance translators. For selection and homogeneity purposes, subjects were selected to be translators with 2-7 years of experience. Individuals with both Bachelors' and Masters' degrees in translation and those who have studied or lived abroad were excluded from the study to minimize the impact of their academic experience and proficiency level. 100 translators selected using purposive sampling method participated in the study. They were divided into two groups and each group finally contained 50 subjects. Group 1 and group 2 contained subjects with and without a degree in translation, respectively.

\subsection{Data Collection Procedures}

First, the study participants answered the demographic questions. Then, both groups were asked to complete a translation task in 30 minutes. The translations were assessed and scored based on Waddington's model D. To do so, a paragraph containing 246 words was given to be translated into Persian; the text was part of the Orwell's 1984 novel. The scores were entered in SPSS 21.0 for further statistical analysis.

\subsection{Data Analysis}

After data entry, the appropriate statistical analysis including descriptive statistics (Frequency, Percentage, Mean and Standard Deviation) were used to analyze demographic data; in order to investigate the research hypothesis, inferential statistics including independent sample t-test was used.

\section{Results}

\subsection{Reliability of the Measure}

The reliability of the study measure was estimated as a preliminary step by Chronbach's alpha which supported the previous reliability findings of the instrument developers. The reliability of Waddington's model D was calculated to be 0.82 .

\subsection{Results of the Descriptive and Inferential Statistics of Variables}

For selecting the correct statistical procedure in this study, the normality of the scores was initially checked which means that the scores on the dependent variable should normally distribute. The following normal Q-Q Plot showed that the distribution of scores was reasonably normal. Since the normality assumption was met, the tests used in this study were kind of parametric techniques.

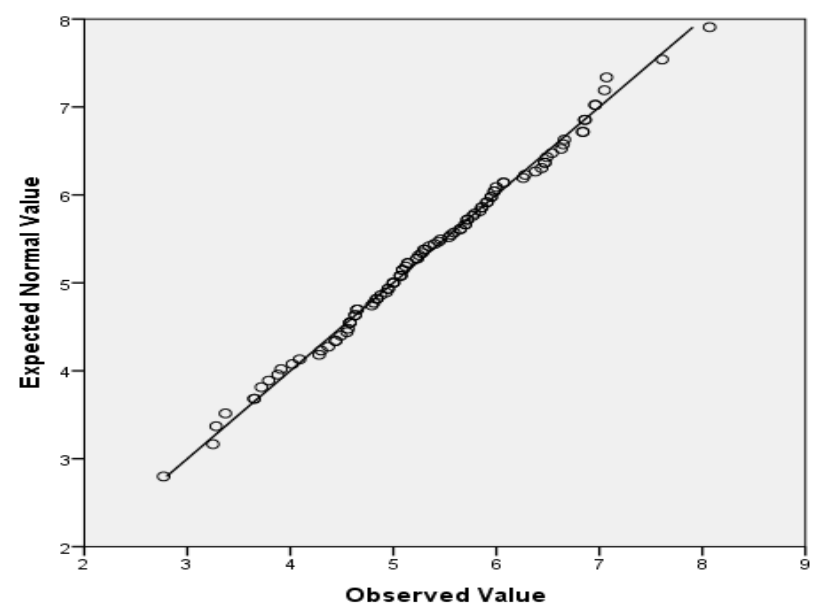

Figure 1. Q-Q plot for the normality of the scores

A total of 100 translators completed the questionnaires. The mean age and years of experience of the participants was 28.2 and 4 years (SD 6.8 and 28.8), respectively. Table 1 summarizes the results of descriptive statistics of the variables. 
Table 1. Descriptive statistics of variables

\begin{tabular}{|c|c|c|c|c|c|}
\hline & workplace & gender & $\begin{array}{l}\text { Academic } \\
\text { experience }\end{array}$ & Years of experience & age \\
\hline $\mathbf{N}$ & 100 & 100 & 100 & 100 & 100 \\
\hline Mean & & & & 4.0404 & 28.2828 \\
\hline Std. Deviation & & & & 1.95312 & 6.83036 \\
\hline
\end{tabular}

Tables 2 and 3 present the results of scoring the translations based on Waddington's model D which was used to assess the participants' translation quality in each group. As explained in part 3, this scoring system makes use of two subjective (holistic) and objective (error analysis) scoring methods, respectively. According to table 2, mean holistic, objective and total score of participants in group 1 was 5.3, 5.7 and 5.5 with (SD 1.1), (SD 1.3) and (SD 1), respectively. On the other hand, mean holistic, objective and total score of participants in group 2 was $5.1,5$ and 5.1 with (SD 0.9), (SD 1) and (SD 0.9), respectively. Mean total score in groups 1 and 2 was finally calculated to be 5.5 and 5.1 with (SD 1) and (SD 0.9), respectively.

Table 2. Descriptive statistics of variables (Total score)

\begin{tabular}{lllll}
\hline & & N & Mean & SD \\
\hline Group 1 & Holistic & 50 & 5.3200 & 1.11465 \\
& Objective & 50 & 5.7120 & 1.34387 \\
& Total score & 50 & 5.5944 & 1.07847 \\
\cline { 2 - 4 } Group 2 & Holistic & 50 & 5.1800 & .98333 \\
& Objective & 50 & 5.0820 & 1.08377 \\
& Total score & 50 & 5.1114 & .91117 \\
\hline
\end{tabular}

Table 3. Mean and Std. Deviation of variables (Total score)

\begin{tabular}{lllll}
\hline & & $\mathrm{N}$ & Mean & SD \\
\hline Total score & Group 1 & 50 & 5.5944 & 1.07847 \\
& Group 2 & 50 & 5.1114 & .91117 \\
\hline
\end{tabular}

The results of independent sample t-test are presented in Table 4 as a way to analyze the relationship between translators' academic degree and their translation quality.

Table 4. Independent samples test

\begin{tabular}{|c|c|c|c|c|c|c|c|c|c|c|}
\hline & & \multicolumn{4}{|c|}{$\begin{array}{l}\text { Levene's Test } \\
\text { for Equality } \\
\text { of Variances }\end{array}$} & \multicolumn{3}{|c|}{ t-test for Equality of Means } & \multirow{2}{*}{\multicolumn{2}{|c|}{$\begin{array}{l}95 \% \text { Confidence } \\
\text { Interval }\end{array}$}} \\
\hline & & \multirow[t]{2}{*}{$\mathbf{F}$} & \multirow[t]{2}{*}{ Sig. } & \multirow[t]{2}{*}{$\mathbf{t}$} & \multirow[t]{2}{*}{ df } & \multirow[t]{2}{*}{$\begin{array}{l}\text { Sig. } \\
\text { (2-tailed) }\end{array}$} & \multirow[t]{2}{*}{$\begin{array}{l}\text { Mean } \\
\text { Difference }\end{array}$} & \multirow[t]{2}{*}{$\begin{array}{l}\text { Std. Error } \\
\text { Difference }\end{array}$} & & \\
\hline & & & & & & & & & Lower & Upper \\
\hline \multirow[t]{2}{*}{ score } & $\begin{array}{l}\text { Equal } \\
\text { variances } \\
\text { assumed }\end{array}$ & 1.779 & .185 & 2.419 & 98 & .017 & .48300 & .19967 & .08677 & .87923 \\
\hline & $\begin{array}{l}\text { Equal } \\
\text { variances not } \\
\text { assumed }\end{array}$ & & & 2.419 & 95.341 & .017 & .48300 & .19967 & .08663 & .87937 \\
\hline
\end{tabular}


According to this table, there is a significant relationship between translators' academic experience and their translation quality (sig 2-tailed $=0.017$ ) which depicts that the translation quality of translators with academic experience was significantly better than that of those without academic experience.

\section{Discussion}

Hypothesis: There is a significant relationship between translator's academic experience and their translation quality.

The results of the independent sample t-test presented in Table 4 as a way to analyze the relationship between translator's academic experience and their translation quality. These results reveal that there is a significant relationship between translator's academic experience and their translation quality $(\mathrm{p}<0.05)$.

Thus the hypothesis of the study could not be rejected. This looks quite natural as the participants with a degree in translation had undergone teaching programs, had experienced translation in an academic environment by applying certain theories and strategies. This finding is of great importance since one can conclude that translation should be acquired like any other skill and translator training programs should be academically followed. This could be more justified with the fact that translators deal with certain translation tasks and problems for which certain strategies and techniques have been theoretically provided in academic materials and environment.

As mentioned before, on the one hand, there is a great need for competent translators. Previously, translating mostly meant literary translation but now great economic, political, commercial, technical, and scientific demands call for training competent translators. Such a huge demand necessitates a planned and organized approach, the basic step of which is the mastery over theoretical frameworks.

On the other hand, according to Cozma and Dejica-Cartis (2013) while people tend to specialize in as few as narrow areas as possible, translators are expected to do exactly the opposite; they are supposed to have a very good knowledge of all the domains with which their work interferes. This means that the translators' profession involves a lot of pressure nowadays, and this pressure is also felt by the translation students, who expect to receive solid and complex training meant to enable them to face the challenges of translating in the real world. Most of the students also maintain that they expect their teachers to give them the opportunity of acquiring various specific skills and knowledge associated with their future profession to cope with the unfamiliar or the difficult character of the texts to be translated.

Therefore, being aware of theoretical knowledge as well as having a general knowledge of other disciplines may positively affect the translators' performance and practice. In other words, translators transit knowledge from theory to practice. By doing this, they become aware of why the translation strategies, skills or information are essential, and this gives them the opportunity to utilize the materials they have theoretically learned, in real life situations.

\section{Conclusions}

A brief review of the literature indicates that translators' degree in translation, academic experience and academic knowledge positively affect the quality of the translation product, the process of translating and producing a good translation; these findings are further supported by the results of the present study.

Our results are in agreement with the results of similar studies by Shojaee and Sahragard (2012), Farahzad (2010), Malkiel's (2006), Saridakis and Kostoupolou's (2003). Our results are also in agreement with the results reported by the committee on cultural psychiatry group for advancement of psychiatry (2002), Dongfeng and Dan (1999) and Albustan (1993).

The conclusions drawn indicate that translators can acquire a higher quality translation through further training in translation courses, translation theories and techniques and problem-solving strategies included in the academic environment. Another implication of this study is that a translation task could be better completed by translators with academic experience in Translation Studies. It is hoped that the findings of the present study will open new horizons for translation trainees and translation trainers, leading to a better insight into the role of individual differences in the act of translating.

\section{Limitations of the Study}

Having acknowledged the limitations of this study, a number of limitations are listed below:

1) The first limitation of this study was lack of sufficient prior research studies on the topic.

2) Another limitation concerns the sample size and lack of available and/or reliable data and access to translators, 
which might be a significant obstacle in finding a trend and a meaningful relationship.

3) As translation quality assessment is still under research and under controversy, the rationale for using each model of quality assessment in translation is open to discussion or may be challenged as a factor to have been influencing the results of such studies.

\section{Suggestions for Future Research}

For those interested to conduct further studies pertinent to the theme of the present research, the following topics are suggested:

1) A similar study can be done to investigate the usefulness of academic courses and educational materials taught in the universities and the performance of the students from a quality point of view.

2) Other studies could be done with the role of various demographic factors such as gender, age, and socioeconomic background, which may have influence on the quality of translation and their interaction with academic experience.

\section{Acknowledgments}

This paper was extracted from a dissertation submitted for Master's degree in English Translation to the department of English, Marvdasht branch, Islamic Azad University in May 2015.

\section{References}

AlBustan, S. A. (1993). Quality And Efficiency Factors in Translation. Dissertation Submitted for the Degree of $\mathrm{Ph}$. D Faculty of Arts University of Glasgow July 1993.

Cozma, M., \& Dejica-Cartis, D. (2013). A psychological approach to professional translator education. Social and Behavioral Sciences, 84, 895-899. http://dx.doi.org/10.1016/j.sbspro.2013.06.669

Group for the Advancement of Psychiatry. (2002). Cultural assessment in clinical Psychiatry. American Psychiatric publishing.

Dongfeng, W., \& Dan, S. (1999). Factors Influencing the Process of Translating. Meta: Translators' Journal, 44(1), 78-100. http://dx.doi.org/10.7202/004616ar

Farahzad, F., Azhideh, P., \& Razmjou, L. (2010). Translation Quality and Awareness of Functional Translation Theories. Iranian Journal of Applied Language Studies, 2(1).

Holljen, M. (1999). Translation Studies at a Crossroads Educating translators in minor language communities-a key element in the language planning of modern Norwegian. Translation journal, 3(1).

Iida, A. (2008). Individual differences in the translation process: Differences in the act of translation between two groups of EFL Japanese students. Translation Journal, 12(3).

Karimnia, A., \& Mahjubi, M. (2013). Individual differences and quality of translation: A personality-based perspective. Psychology of Language and Communication, 17(1), 37-64. http://dx.doi.org/10.2478/plc-2013-0003

Malkiel, B. (2006). The effect of translator training on interference and difficulty. Target, 18(2), 337-366. http://dx.doi.org/10.1075/target.18.2.07mal

NG, T. W. H., \& Feldman, D. C. (2009). How broadly does education contribute to job performance? Personnel psychology, 62, 89-134. http://dx.doi.org/10.1111/j.1744-6570.2008.01130.x

Saridakis, I. E., \& Kostopoulou, G. (2003). Methods and the role of revision in academic and professional environments of translation. 4th FEDER. CEN. TR. I. Conference, Bologna 10-1.

Shojaee, F., \& Sahragard, R. (2012). The Effect of Risk-Taking on Translation Quality of English Translation Students. The $10^{\text {th }}$ International TELLSI Conference, Shahid Beheshti University, Mehr 25-28, 1391 (October 16-19).

Waddington, C. (2001). Different methods of evaluating student translations: The question of validity. In Meta, XLVI, 2, 311-325. http://dx.doi.org/10.7202/004583ar

\section{Copyrights}

Copyright for this article is retained by the author(s), with first publication rights granted to the journal.

This is an open-access article distributed under the terms and conditions of the Creative Commons Attribution license (http://creativecommons.org/licenses/by/3.0/). 